\title{
O processo empreendedor em empresas criadas por necessidade
}

\section{The entrepreneurial process in firms created out of necessity}

\author{
Janis Elisa Ruppenthal ${ }^{1}$ \\ José Eduardo Cimadon ${ }^{1}$
}

\begin{abstract}
Resumo: O ofício de criar empresas é inerente aos empreendedores. Quando a motivação é a necessidade, o risco de insucessos aumenta muito. Nesse trabalho, busca-se conhecer, compreender e compartilhar os aprendizados de um grupo de empreendedores que passaram por essa situação e obtiveram sucesso. A partir do ponto de vista teórico dos autores que tratam do pragmatismo dos processos empreendedoriais, o estudo de caso buscou, no decurso das entrevistas com os empresários, a relação entre as teorias e práticas. Instituída a relação, sugere-se um modelo de atuação empreendedora que possa orientar outros empresários em situação semelhante. Ao final, observou-se que ter seu próprio negócio os motivou e a atenção aos feedbacks os estimulou para as mudanças. O elevado grau de coerência entre o empreendedor, seu negócio e o ambiente favoreceram a situação. Enquanto desenvolviam experiências empreendedoriais, essas pessoas, influenciadas por diferentes modos de atuação, alteraram os seus, levando-as a desenvolver o processo empreendedor. Diante disso, pode-se dizer que suas atitudes catalisaram as mudanças, caracterizadas pelo elevado grau de assertividade.
\end{abstract}

Palavras-chave: Empreendedorismo. Criação de empresas por necessidade. Processo empreendedor.

\begin{abstract}
Creating firms is an inherent entrepreneurial spirit. When necessity is the motivation, the risk of failure is high. The objective of this study is to understand and share the learnings and experiences of an entrepreneurial group that was faced with this challenging situation and reached success. From the theoretical point of view of the authors who dealt with the entrepreneurial process, the case study aimed to establish a relationship between theory and practice through interviews with entrepreneurs. Once this relationship was established, a model of entrepreneurial action that can guide other entrepreneurs in similar situations was suggested. It was observed that the idea of having their own business motivated the entrepreneurs and the feedback received stimulated changes. Prudent entrepreneurship, the business created, and the environment favored this situation. While developing entrepreneurial experiences, these entrepreneurs, influenced by different types and styles of management, changed their own management approach and developed the entrepreneurial process. This behavior speeded up changes leading to high levels of accomplishment.
\end{abstract}

Keywords: Entrepreneurship. Firms created of necessity. Entrepreneurial process.

\section{Introdução}

O Brasil tem se posicionado no topo das listas dos países mais empreendedores. Fato esse que pode ser interpretado como um indicador de crescimento econômico e de um ambiente propício à criação de novas empresas. Porém, ao ser analisado com maior profundidade, esse fato remete a uma realidade na qual se observa que para cada empresa que surge devido a uma oportunidade outra surge por necessidade de ocupação e renda de seus criadores.

Essa dicotomia está evidenciada nos relatórios executivos Global Entrepreneurship Monitor - GEM (2005, 2006, 2007, 2008), que diferencia os empreendedores conforme a motivação pela qual criaram suas empresas:
Empreendedores por oportunidade: motivados pela percepção de um nicho de mercado em potencial e Empreendedores por necessidade: motivados pela falta de alternativa satisfatória de ocupação e renda. (GLOBAL..., 2005, p. 13)

Acredita-se que as Micro e Pequenas Empresas - MPEs criadas por necessidade estejam mais propensas ao fracasso. Porém, muitas não atendem a essa expectativa. Nesse caso, que fatores determinam sua prevalência?

Pesquisadores das áreas do comportamentalismo (WEBER, 1930; McCLELLAND, 1971; TIMMONS, 1973; PINCHOT, 1989) e da economia (CANTILLON,

\footnotetext{
${ }^{1}$ Programa de Pós-Graduação em Engenharia de Produção, Centro de Tecnologia, Universidade Federal de Santa Maria - UFSM, Av. Roraima, 1000, Cidade Universitária, Camobi, CEP 97105-900, Santa Maria, RS, Brasil, e-mail: janisr@smail.ufsm.br
} 
1755; SAY, 1983, 1815, 1816, 1839; SCHUMPETER, 1954, 1997; BAUMOL,1968, 1990, 1993; BUCHANAN; DI PIERRO, 1980) têm estudado o comportamento humano e a forma como estabelecem relações consigo mesmo e com os seus negócios, e como ambos relacionam-se com o ambiente. Entre esses estão os autores dos modelos conceituais que orientam este trabalho e evidenciam o viés empreendedor dos sujeitos da pesquisa: a teoria visionária (FILION, 1993); a teoria empreendedora dos sonhos (DOLABELA, 2003); e os fundamentos cognitivos do empreendedorismo (BARON; SHANE, 2007; STERNBERG, 2004).

Objetiva-se conhecer os comportamentos gerenciais determinantes do sucesso desses empreendedores, procurar esclarecer os motivos pelos quais uma ou várias decisões foram tomadas, como foram implementadas e quais resultados foram alcançados. $\mathrm{E}$, por fim, propor um modelo de atuação empreendedora que possa ser utilizado por outros empresários.

\section{O processo empreendedor}

Historicamente o empreendedor tem sido relacionado ao sonho de conquistar algo importante, à necessidade de realização, ao desenvolvimento econômico, à inovação, ao aproveitamento de oportunidades para gerar novos negócios e concretizar visões (SAY, 1983), (SCHUMPETER, 1997), (MCCLELLAND, 1972), (DOLABELA, 1999a, 2000), (FILION, 2000), (DORNELAS, 2005), (BARON; SHANE, 2007). Esses empreendedores, segundo Filion apud Dolabela (1999a), podem ser voluntários porque têm motivação para empreender ou involuntários porque são forçados a empreender por motivos alheios à sua vontade, tais como desempregados, imigrantes, herdeiros entre outros.

As altas taxas de insucesso das MPEs no Brasil, em que, de acordo com Global Entrepreneurship Monitor (2008), cerca de 60\% do total de novas empresas não sobrevivem por mais de três anos, levaram à implementação de ações visando reverter essa situação. Assim, surgiu o seguinte questionamento: o empreendedorismo pode ser ensinado e, portanto, aprendido? Ou ele é algo inerente às pessoas? Pesquisadores como Schumpeter (1997), McClelland (1971), Druker (1998), Filion (1991), Dolabela (1999a), Sternberg (2004), (2004), Mitchell et al. (2007), Baron e Shane (2007), entre outros propõem que ao indivíduo compete o esforço da percepção e desenvolvimento de suas, características, habilidades, interesses pessoais, crenças e valores. Tendo, portanto, na educação formal ou informal um dos veículos para o aprendizado e desenvolvimento das práticas empreendedoras.

O empreendedorismo alimenta-se de oportunidades, porém, é comum confundir-se uma ideia com oportunidade e assim surge mais uma empresa.
Segundo Dolabela (1999b, p. 4), “[...] boas ideias não são necessariamente oportunidades e não saber distinguir umas das outras é uma das grandes causas de insucesso.". Conhecer e utilizar comportamentos que auxiliaram na jornada empreendedora desencadeia um processo de modelagem que permite o registro e a incorporação desses traços de comportamento ao patrimônio vivencial dos empresários aprendizes.

Não há unanimidade sobre a definição de empreendedorismo como uma área de estudos ou como uma atividade com a qual pessoas se ocupam. Dessa forma, Shane e Venkatareman (2000), Baron e Shane (2007) sugerem que o empreendedorismo, como uma área de negócios, busca entender como surgem as oportunidades para criar algo novo. E, além disso, de que forma as oportunidades são descobertas ou criadas por indivíduos que, a seguir, usam meios diversos para explorá-las ou desenvolvê-las, produzindo, assim, uma ampla gama de efeitos.

A perceptível retomada nos estudos sobre empreendedorismo no campo acadêmico e fora dele deve-se a múltiplos fatores. Entre os quais, Serafin e Leão (2007) citam o crescimento da colaboração interdisciplinar entre economistas, sociólogos, antropólogos e cientistas políticos, a atenuação da força da ideologia marxista - que não faz distinção entre capitalistas e empreendedores - e que tende a incluir ambos a um julgamento fortemente crítico. E, também, o reconhecimento do papel fundamental que as pequenas empresas familiares e o empreendedorismo social possuem no desenvolvimento econômico de um país.

Há ainda o debate sobre os elementos que diferenciam empreendedores de operadores de pequenos negócios. Filion (1999) identificou diferentes sistemas de atividades que estruturam o processo de gerenciamento nos dois grupos. Nos empreendedores, destacaram-se visão, projeto, animação, monitoração e aprendizagem, enquanto que nos operadores, destacaram-se seleção, desempenho, atribuição, alocação, monitoração e ajuste.

\subsection{A teoria empreendedora dos sonhos}

A teoria é composta de dois movimentos: sonhar e buscar a realização do sonho (DOLABELA, 2003). O ato de sonhar envolve imaginar algo que dá estrutura, é estimulante e articula sinergicamente a visão, valores, competências, desejos, preferências e autoestima, experimentados no desenvolvimento de projetos que levem o empreendedor ao sentimento de autorrealização. O sonho estruturante deve ser congruente com o sistema de valores e a forma de ser de quem sonha, e ainda ser factível.

Considerando-se que os comportamentos são condicionados por situações, circunstâncias e condições e que surgem de acordo com a "situação 
empreendedora" na qual a pessoa se envolve, é recomendável ao indivíduo

[...] colocar-se em uma situação empreendedora, em que a emoção o instigue à busca e realização dos sonhos e desejos, disparando os comportamentos mencionados. (DOLABELA, 2003, p. 40)

Isso faz com que o empreendedor acesse e utilize esses comportamentos.

\subsection{A teoria visionária}

A teoria visionária de Filion (1991) explica como, a partir de uma ideia de produto ou serviço, forma-se um novo negócio e são estabelecidas as relações entre esses empreendedores, seus negócios, o ambiente em que estão inseridos e a importância dessas relações. Para Filion (2004, p. 43), a visão é

[...] uma imagem, projetada no futuro, do lugar que se quer ver ocupado pelos produtos no mercado e do tipo de organização necessária para consegui-lo.

As três categorias de visões, emergente, central e complementar, reagem entre si de forma intensa e constante.

Para evoluir de uma categoria para outra, o empreendedor precisa de um alto nível de articulação pessoal, coerência e tenacidade, todos eles importantes fatores para o sucesso ou o fracasso de sua estratégia. (FILION, 1993, p. 56).

As visões emergentes surgem de um grupo de possibilidades de negócios e [...] são formadas em torno de ideias e conceitos de produtos e/ou serviços imaginados pelo empreendedor. (FILION, 1993, p. 53).

$\mathrm{Na}$ medida em que se tornam mais claras, uma delas adquire maior importância nos planos do empreendedor, que passa a se dedicar com maior afinco na sua investigação, tornando-a dessa forma a sua visão principal. Para alguns empreendedores existe uma continuidade entre suas visões emergentes e a central. (FILION, 1993, p. 54). A visão central divide-se em visão externa e interna. A primeira permite projetar o lugar que o empreendedor pretende ocupar com seu produto ou serviço no mercado. Já a visão interna diz respeito ao tipo de organização da qual ele necessita para ocupá-lo. Para Filion (1993, p. 54),

[...] quanto mais o componente interior da visão permite a uma organização tomar uma forma que incorpore as inovações do componente exterior, tanto mais bem-sucedido o empreendedor.

É preciso considerar que os componentes devem ser claros e coerentes, realistas e viáveis. Para que gerem confiabilidade e sustentabilidade ao processo.
As visões complementares constituem-se numa série de atividades gerenciais de apoio ao desenvolvimento da visão central, introduzidas pelos componentes internos e externos. Quanto maior a habilidade de se comunicar e o conhecimento no campo que pretende atuar, maior será a capacidade para definir as visões complementares.

Acredita-se que o processo de desenvolvimento da visão seja o principal elemento a ser dominado pelo empreendedor. Uma vez que a visão necessita ser checada, compartilhada e aprovada, o empreendedor deverá dispor de habilidades de persuasão e de comunicação.

O conceito de si e do mundo influencia e condiciona o processo visionário, projetando um futuro baseado nas crenças atuais. Para Filion (1991, 1993), a visão de mundo (e de si) é a base sobre a qual se desenvolve o processo de estabelecimento da visão do empreendedor e que, assim como os valores, não são fixos, sendo continuamente reformulados à luz do contexto em que o indivíduo opera ou decide operar.

A energia é o combustível que sustenta a marcha empreendedora. Filion (1991, p. 65) a conceitua como "[...] o tempo alocado para atividades profissionais e a intensidade com que elas são executadas.". A visão e o conceito de si influenciarão a frequência e intensidade de energia que o empreendedor investirá em sua atividade profissional, e em que momento de sua vida. Para Dolabela (2003), a energia decorre da adequação entre o conceito de si e a visão.

A liderença é resultante do conceito de si, da energia, da compreensão do setor, da visão e das relações, mas reciprocamente, influencia esses fatores (FILION, 1991; DOLABELA, 1999a). A capacidade de ocupar e manter-se na posição de líder afeta o desejo de realizar. Fato esse que determina a amplitude da visão do empreendedor. Sendo influenciadora e influenciável, dependente do meio e das circunstâncias, a liderança é mutável e parece surgir da evolução gradual do indivíduo e da empresa, gerando poder e facilitando o estabelecimento e a realização das visões.

Dizer que é possível perceber uma oportunidade e desenvolver uma visão sem compreender o setor de negócios a que ela pertence é, no mínimo, temerário (DOLABELA, 1999a). A presença dos elementos conceito de si, energia, liderança e relações, influenciando e sendo influenciados contribuem fundamentalmente para a compreensão do setor.

O sistema de relações, principalmente as familiares, é considerado o sistema básico inicial da motivação empreendedor. Dessa forma, o sistema de relações, aparentemente, é o fator mais influente para explicar a evolução da visão (FILION, 1991). Essas relações ocorrem em três níveis: primário, secundário e terciário. As relações primárias, ligadas a sensações afetivas, intelectuais e de lazer influenciam o conceito de si. As relações de nível secundário formam-se 
em torno de atividades pontuais: trabalho, política, sociais, religiosas, entre outras. As relações terciárias são estabelecidas com a finalidade de atender a uma necessidade específica em determinada área de interesse (FILION, 1991).

\subsection{A inteligência empreendedor}

Os empreendimentos bem sucedidos originam-se de um somatório de eventos, nem sempre percebidos. São, portanto, decorrentes de oportunidades que resultam de frequentes mudanças na tecnologia ou nas condições políticas, sociais e demográficas que geram o potencial para criar algo novo (BARON; SHANE, 2007). O passo seguinte, a exploração dessas oportunidades por meio de inovações, requer uma mistura de aspectos analíticos, criativos e práticos da inteligência, que, ao serem combinados, constituem a inteligência para o sucesso (STERNBERG, 2004). Considerada a principal competência do empreendedor, a inteligência emerge a partir de três conceitos: a formação de novas ideias, a criatividade e a capacidade de reconhecer oportunidades.

Esses conceitos encontram-se ancorados na capacidade intrínseca dos indivíduos de acessar, armazenar, processar e utilizar informações, intimamente ligada ao sistema cognitivo humano. A geração de novas ideias acontece quando indivíduos utilizam o conhecimento existente que adquiriram e armazenaram para gerar algo novo (BARON; SHANE, 2007). Ou seja, o fenômeno acontece a partir de um estímulo e da qualidade da resposta, que é diretamente proporcional ao estoque de conhecimento desses indivíduos.

A memória subdivide-se em vários sistemas: a memória de trabalho, de capacidade limitada e de curto prazo; a memória de longa duração que armazena grande quantidade de informações por logos períodos de tempo; e a memória procedural, responsável pelo armazenamento de informações dificilmente verbalizáveis. Essa memória talvez demonstre porque os empreendedores têm dificuldades para explicar como ocorre a identificação e a opção por assumir uma determinada oportunidade (BARON; SHANE, 2007).

Além da memória, há estruturas temporárias: os esquemas, que são estruturas mentais cognitivas representativas de nosso conhecimento e hipóteses a respeito de aspectos específicos do mundo. Já os protótipos são estruturas mentais cognitivas formadas por representações mentais abstratas idealizadas que capturam a essência de uma categoria de objetos. Ambas as estruturas criadas para auxiliar a compreender e integrar novas informações com outras anteriormente adquiridas podem induzir ao erro, como em situações nas quais devem ser tomadas decisões importantes e dispõe-se de pouca informação (BARON; SHANE, 2007).

Resultante de processos cognitivos básicos, a criatividade pode ser definida considerando dois aspectos-chave: os itens ou ideias produzidos são tanto novos, originais, não esperados, como apropriados ou úteis, pois atendem a restrições relevantes. Dentre esses processos, dois são centrais: Um primeiro envolve a expansão de certas estruturas mentais internas, cuja função é facilitar o processo de recuperar e utilizar as informações armazenadas na memória de longo prazo - os conceitos. E um segundo que envolve as operações de algumas características da inteligência humana. Essa organização de informações pode afetar positivamente o desempenho mental, permitindo que as matérias-primas, das quais as novas ideias podem surgir, sejam mais facilmente armazenadas e acessadas. E negativamente, limitando o pensamento a círculos viciosos mentais, inibindo a criatividade (BARON; SHANE, 2007).

A inteligência humana é definida por Antunes (2000, p. 11) como "[...] a capacidade cerebral pela qual conseguimos penetrar na compreensão das coisas escolhendo o melhor caminho.”. Baron e Shane (2007, p. 73) a definem como

[...] as habilidades de um indivíduo de compreender ideias complexas, de adaptar-se ao mundo ao seu redor, de aprender com a experiência, de envolver-se com várias formas de raciocínio e de superar obstáculos.

A multiplicidade da inteligência humana, defendida por Goleman (1995) abrange sete tipos diferentes de inteligências: a vivacidade verbal, a matemática-lógica, a espacial, a cinestésica, a musical, a interpessoal e a intrapsíquica. Antunes (2000) acrescenta a naturalista e cita Machado (1996) ao acrescentar uma nona - a pictórica.

Para Sternberg (2004), a obtenção do sucesso empreendedor é influenciada pela utilização de uma fusão estratégica das inteligências prática, analítica e criativa. Baron e Shane (2007) acrescentam ainda a inteligencia social. E Sternberg (2004), embora não a incluía, comenta que empreendedores bem sucedidos parecem possuir um grau mais elevado de inteligência social que os mal-sucedidos.

O reconhecimento de oportunidades é considerado uma das etapas iniciais do processo empreendedor e ocorre de uma sequência de eventos envolvendo novas ideias, criatividade, motivação e muita energia. Essa sequência de eventos sugere o motivo pelo qual se deve examiná-lo como um processo composto de diversas questões-chave (BARON; SHANE, 2007). A primeira procura compreender como as pessoas identificam oportunidades. A segunda trata do porquê algumas pessoas são melhores que outras para identificar oportunidades. A terceira discute por 
que alguns indivíduos são melhores em decidir quais oportunidades são melhores e poderão gerar maiores ganhos econômicos e por fim, se as oportunidades existem de fato ou se são criadas pela mente humana. Para Baron e Shane (2007, p. 78), “[...] as oportunidades, tanto existem lá fora, como também são resultado da criação do pensamento humano.".

Considerando-se que o reconhecimento de oportunidades passa pelo acesso e adequada utilização das informações, e que as pessoas, por possuírem características individuais diferenciadas, obtêm e utilizam informações de maneira diferente, pode-se esperar que determinados indivíduos desfrutem de uma maior acessibilidade a informações úteis no processo de identificação de oportunidades. Em resposta a essas questões, pode-se dizer que o reconhecimento de oportunidades tem relação direta com a capacidade de acessar e utilizar informações.

\section{Delineamento metodológico}

Considerando que, nessa pesquisa, o fenômeno de interesse não pode ser estudado fora de seu ambiente natural, o problema é pouco conhecido e a exploração caracteriza a pesquisa, concluiu-se que a abordagem adequada é a qualitativa (TRIVIÑOS, 2006).

A estratégia de pesquisa utilizada foi o estudo de caso, e o objetivo foi o de aumentar o entendimento sobre eventos reais e contemporâneos. Além de procurar esclarecer os motivos pelos quais uma ou várias decisões foram tomadas, como foram implementadas e quais resultados foram alcaçados (MIGUEL, 2007; YIN, 2001). Dessa forma, os resultados são válidos somente para o caso que se estuda, porém seu valor é fornecer o conhecimento detalhado de uma realidade delimitada, e que os resultados possam levar à formulação de hipóteses para o encaminhamento de outras pesquisas.

A partir de um plano de pesquisa pré-estabelecido, foram utilizados como procedimentos a entrevista estruturada e a semiestruturada, além da observação direta não participante, os artefatos físicos e culturais, e os documentos e registros (GIL, 1996; MIGUEL, 2007). As empresas foram intencionalmente escolhidas na região centro-oeste do Paraná para esse estudo e, como sujeitos entrevistados, os seus gestores. A escolha foi motivada pelo fato de que essas empresas foram criadas ou adquiridas por necessidade, pela semelhança no seu porte e pelo fato de que elas representam a principal fonte de sustento dos seus donos. Papel que ainda cumprem, diferenciando-as das criadas com o mesmo fim, mas que já não mais existem.

A pesquisa in loco, segundo Richardson (1999), é possivelmente a forma mais comum de descrever as características e medir determinadas variáveis. Assim, optou-se por uma abordagem que contemplasse inicialmente os motivos pelos quais a empresa foi criada. Os sujeitos da pesquisa foram determinados a partir dos seguintes critérios: empresários cujas empresas estavam estabelecidas e em operação há, pelo menos, três anos e meio, ainda não haviam completado o décimo ano de existência, e tinham pertencido inicialmente a grupos culturais diferenciados. Porém, todos eles, em algum momento anterior ao da criação ou aquisição da empresa, passaram, necessariamente, por alguma dificuldade financeira, sendo esse o principal motivo e origem da necessidade da criação das empresas selecionadas.

$\mathrm{O}$ cuidado para que os sujeitos pesquisados apresentassem diferentes níveis culturais, de escolaridade e de capacitação técnica foi devido ao fato de acreditar-se que a formação técnica na área empresarial influencie seu desempenho gerencial, dificultando ou facilitando a sua trajetória empresarial. Além disso, os sujeitos foram consultados quanto ao fato de aceitarem fazer parte da pesquisa, entendendo seu testemunho como contribuição à compreensão dessa realidade. Os empresários e empresas selecionados foram assim identificados: Empresa A - Comércio de cosméticos; Empresa B - Escola de informática; Empresa C - Oficina de autoelétrica; Empresa D - Instalação e manutenção de ar condicionado automotivo; Empresa E - Comércio de materiais de construção.

Elaborou-se um roteiro procurando-se abranger o maior número de aspectos possíveis, objetivando demonstrar as relações, e as consequentes implicações, entre a história de vida dos entrevistados, os históricos empresariais e o meio em que atuam. Procurou-se ainda, identificar as situações gerais e específicas que envolveram suas trajetórias empresariais e de que forma resultaram na realidade atual, tais como escolhas, ações e consequências. As entrevistas realizadas abordaram as seguintes questões: a) identificação dos sujeitos da pesquisa, empresários e empresas; b) escolaridade do empresário, bem como suas relações com o aprendizado, com a escola formal e com outras formas de aprendizagem; c) tipo de empresa e conhecimento do negócio; d) conhecimento sobre empreendedorismo; e) ocupação anterior; f) histórico de vida, sistema de relações parentais e grupos a que pertenceu; g) relação do empresário com as pessoas, com a empresa e com o meio em que atua; $h$ ) capacidade de perceber as retroinformações e delas fazer uso. Os resultados foram organizados de forma que permitissem a caracterização dos sujeitos da pesquisa.

É conhecida a dificuldade em concentrar o universo das informações e do saber descritos. Dessa forma, para dar razão pragmática aos fatos narrados a partir da literatura impressa, optou-se pela realização das entrevistas nas empresas. Os sujeitos da pesquisa foram intencionalmente selecionados como forma de direcionar as entrevistas àquele grupo de empresas. 
Com a intenção de obter uma análise mais aprofundada dos fatos e assim atender os objetivos pré-estabelecidos nessa pesquisa, optou-se por realizar duas entrevistas. Na primeira entrevista, procurou-se identificar, genericamente, nos entrevistados, os aspectos de duas teorias que fundamentaram essa pesquisa: A teoria empreendedora dos sonhos (DOLABELA, 2003) e a teoria visionária (FILION, 1993). Enquanto que, na segunda entrevista, priorizou-se o desenvolvimento dos empreendedores e de seus negócios, além da possível ativação da inteligência empreendedor, fundamentada nas teorias de vários autores (BARON; SHANE, 2007; STERNBERG, 2004; MITCHELL et al., 2007). Esse procedimento visou fortalecer a construção do modelo proposto.

\section{Perfil empreendedor}

As informações obtidas dos empresários entrevistados são apresentadas em tópicos que procuram obedecer a sequência proposta pelos modelos conceituais desse trabalho. Dessa forma, as informações coletadas, na primeira entrevista, são apresentadas resumidamente nos Quadros 1, 2, 3 e 4 por meio de anotações pontuais a respeito da teoria empreendedora dos sonhos, da teoria visionária e do plano de negócios.

As empresas, identificadas no Quadro 1, foram criadas pelos seus donos atuais, que continuavam as administrando.

A maior incidência de empresários do sexo masculino ocorreu por acaso e não deve ser considerada como indício de sua predominância no meio empresarial. Com exceção do ex-motorista que era autônomo, os sujeitos da pesquisa são ex-funcionários, com diferentes graus de escolaridade. Observou-se que a maioria deles detinha alguma experiência no ramo, fator que pode ter facilitado o caminho percorrido. O Quadro 2 resume a caracterização dos empresários entrevistados.

Os elementos da teoria empreendedora dos sonhos e da teoria visionária, descritos no Quadro 3, na medida em que são declarados, conferem-lhes pragmatismo. O elemento da teoria empreendedora dos sonhos, manifestado no desejo de ser dono de seu próprio negócio, aparece como mobilizador para a concretização do sonho pessoal dos entrevistados e como impulso inicial para a formação do processo visionário. Na sequência, observa-se que as visões emergente e central confundem-se ao surgirem praticamente ao mesmo tempo. E, ao expressarem o desejo de ter seu próprio negócio, reforçam a motivação.

Apenas depois da empresa já montada, com a diminuição da ansiedade, as visões emergentes retornam e reorientam esses empreendedores para os próximos passos: a implementação de ações voltadas para a realização das visões externas e internas. As visões externas e internas aparecem inicialmente fundidas à visão central, quase sempre de forma desestruturada, não pensada e praticamente não diferenciada. Desenvolvidas a partir de um modelo baseado na conduta de outra pessoa ou empresa já existente e conhecida.

As visões complementares passaram a acontecer depois da abertura da empresa, como consequência das sugestões e necessidades manifestadas pelos clientes. E podem ser consideradas como os principais

Quadro 1. Identificação das empresas selecionadas.

\begin{tabular}{|c|c|c|c|c|c|}
\hline $\begin{array}{c}\text { Características } \\
\text { da empresa }\end{array}$ & $\begin{array}{c}\text { Empresa } \\
\text { "A" }\end{array}$ & $\begin{array}{c}\text { Empresa } \\
\text { "B" }\end{array}$ & $\begin{array}{c}\text { Empresa } \\
\text { “C”” }\end{array}$ & $\begin{array}{c}\text { Empresa } \\
\text { "D” }\end{array}$ & $\begin{array}{c}\text { Empresa } \\
\text { "E” }\end{array}$ \\
\hline $\begin{array}{c}\text { Atividade } \\
\text { principal }\end{array}$ & $\begin{array}{c}\text { Comércio de } \\
\text { cosméticos }\end{array}$ & $\begin{array}{c}\text { Escola de } \\
\text { informática }\end{array}$ & $\begin{array}{c}\text { Oficina de } \\
\text { autoelétrica }\end{array}$ & $\begin{array}{c}\text { Comércio de } \\
\text { materiais de } \\
\text { construção }\end{array}$ & $\begin{array}{c}\text { Comércio e } \\
\text { serviços de ar } \\
\text { condicionado } \\
\text { automotivo }\end{array}$ \\
\hline Tempo de criação & Quatro anos & Seis anos & Cinco anos & Nove anos & Sete anos \\
\hline
\end{tabular}

Quadro 2. Características dos empresários entrevistados.

\begin{tabular}{|c|c|c|c|c|c|}
\hline \multicolumn{7}{|c|}{ Características dos empresários } \\
\hline Sexo & Feminino & Masculino & Masculino & Masculino & Masculino \\
\hline $\begin{array}{c}\text { Eccolaridade } \\
\text { anterior }\end{array}$ & $\begin{array}{c}\text { Pós-graduada } \\
\text { Empregada no } \\
\text { setor }\end{array}$ & $\begin{array}{c}\text { Superior } \\
\text { Desempleto } \\
\text { incompleto }\end{array}$ & $2^{\circ}$ grau completo & $2^{\circ}$ grau completo \\
\hline $\begin{array}{c}\text { Experiência no } \\
\text { ramo }\end{array}$ & $\begin{array}{c}\text { Gerente de loja } \\
\text { do mesmo ramo }\end{array}$ & $\begin{array}{c}\text { Professor de } \\
\text { informática }\end{array}$ & Mecânico & $\begin{array}{c}\text { Empregado no } \\
\text { setor }\end{array}$ & $\begin{array}{c}\text { Motorista de } \\
\text { caminhão }\end{array}$ \\
\hline
\end{tabular}


Quadro 3. Elementos das teorias empreendedora dos sonhos e visionária.

\begin{tabular}{|l|l|}
\hline \multicolumn{1}{|c|}{ Elemento } & \multicolumn{1}{c|}{ Aspectos observados } \\
\hline Sonho mobilizador & - Ter seu próprio negócio \\
& - Ser seu próprio patrão \\
\hline Visão emergente e/ou & - As visões emergente e central confundem-se no desejo de ter seu próprio negócio \\
Visão central & - Criar um negócio em sociedade com um amigo \\
& - Livrar-se de uma situação de desconforto com o antigo patrão \\
& - Aceitar o convite do sogro para iniciar um novo empreendimento e poder \\
\hline Visão externa & - Feedbacks de clientes sobre falta de produtos \\
& - Percebeu que precisava mudar sua empresa para um ponto mais adequado \\
\hline Visão interna & - Percebeu a falta de determinado serviço e depois diversificou \\
& - O espaço subdimensionado prejudicava as vendas \\
& - Ampliou os estoques \\
\hline Visão complementar & - Ampliou o espaço interno para gerar conforto aos clientes \\
& - Ampliou conhecimentos para atender a novas demandas \\
\hline
\end{tabular}

Quadro 4. Elementos da teoria visionária.

\begin{tabular}{|c|c|}
\hline Elemento & Aspectos observados \\
\hline Relações com familiares & - Estímulos positivos e exemplos parentais \\
\hline Relações com objetos sociais & $\begin{array}{l}\text { - Utiliza-se de leituras, cursos, associações de classe, pessoas, feiras e } \\
\text { eventos sociais }\end{array}$ \\
\hline Relações com seu produto/serviço & $\begin{array}{ll}\text { - } & \text { Gosta do que faz } \\
\text { - } & \text { Busca informações } \\
\text { - } & \text { Fica atento às novidades } \\
\text { - } & \text { Altera projetos } \\
\end{array}$ \\
\hline Relações com mercado alvo & $\begin{array}{l}\text { - } \quad \text { Preocupa-se com o cliente e suas necessidades } \\
\text { - } \quad \text { Ouve e utiliza feedbacks } \\
\text { - } \quad \text { Percebe que ainda há espaço a ser ocupado e pretende ocupá-lo }\end{array}$ \\
\hline Relações com sua empresa & $\begin{array}{l}\text { - Gerencia, organiza e orienta } \\
\text { - Ambiente maravilhoso } \\
\text { - Vive a empresa }\end{array}$ \\
\hline Relações com empregados & $\begin{array}{l}\text { - } \quad \text { Gerencia e orienta } \\
\text { - Confia e delega } \\
\text { - É uma grande família } \\
\end{array}$ \\
\hline
\end{tabular}

motivos das frequentes mudanças no mix de produtos, layout, endereço, entre outras.

O sistema de relações, da teoria visionária no Quadro 4, revelou-se um fato presente, motivador e consistente em suas vidas, percebido nos depoimentos pelas revelações sobre o apoio familiar e a vida social, com exceção de um deles que é avesso a eventos sociais.

$\mathrm{O}$ alto grau de identificação pessoal com a atividade facilita o relacionamento com os vários elementos que a compõem: serviços, produtos, ambiente, clientes, empregados, participação em eventos sociais, feiras setoriais e outras áreas de interesse. A influência dos feedbacks recebidos, e declaradamente importantes, ratifica essa impressão.

Dentre os fatos observados, atrai atenção o elevado grau de coerência existente entre o empreendedor, seu negócio e o ambiente em que acontece, conforme exposto no Quadro 5. Essa triangulação, e a forma como ela se desenvolve, atende quase totalmente às necessidades de espaço, afeto e realização profissional da maioria dos entrevistados.

Percebe-se que, em sua maioria, ainda que inconscientes do fato, esses empreendedores adquiriram maior autonomia e ampliaram suas práticas empreendedoriais. Assim como detinham boa parte das características necessárias para lidar 
Quadro 5. Elementos da teoria visionária.

\begin{tabular}{|c|c|}
\hline Elemento & Aspectos observados \\
\hline Conceito de si & $\begin{array}{l}\text { - Considera-se empreendedor e competente } \\
\text { - Não se considera empreendedor } \\
\text { - Considera-se um técnico competente } \\
\text { - Está mudando e tornando-se mais observador }\end{array}$ \\
\hline Energia & $\begin{array}{l}\text { - Apresentam elevado grau de energia, afirmando que poderiam trabalhar mais de } \\
\text { dez horas por dia }\end{array}$ \\
\hline Liderança & $\begin{array}{l}\text { - Buscou um sócio para iniciar seu negócio } \\
\text { - Profissionais da área recorrem a ela para aconselhar-se }\end{array}$ \\
\hline Competência & $\begin{array}{l}\text { - } \text { Sabe que tem e busca mais conhecimento técnico } \\
\text { - } \text { Conhece bem o trabalho técnico - produção } \\
\text { - } \text { Para a produção, o contador orienta outras coisas } \\
\text { - } \text { Adquiriu trabalhando na atividade } \\
\text { - } \text { Comercial, técnica e administrativa }\end{array}$ \\
\hline
\end{tabular}

bem com os elementos de sustentação do processo empreendedor. A ausência de um plano de negócios formal, ou de qualquer outro tipo de ferramenta que lhes permitisse uma consistente análise de viabilidade, é fato comum e revelador da ainda incompleta capacitação empreendedor.

Na segunda entrevista, ao serem convidados a expor suas percepções pessoais, sobre eventuais mudanças na condução de seus negócios, todos confirmaram o fato, acrescentando afirmações do tipo: "modifiquei meus conceitos a respeito de determinados fatos que aconteciam na empresa e com os quais não me importava. Passei a perceber que interferiam muito nos nossos resultados". As mudanças mais importantes, na opinião dos entrevistados, foram:

- Maior capacidade de resolver, rápida e eficazmente, os problemas do dia a dia;

- Maior habilidade de pensar sobre os eventos ocorridos de forma analítica e crítica;

- Percepção, por meio da familiaridade da atividade, que a habilidade de formar novas ideias favorecia o incremento do negócio e possibilitava novas formas de resolver problemas;

- Adequação do relacionamento interpessoal com clientes, fornecedores e funcionários gerou benefícios imediatos.

Essas mudanças são percebidas e compreendidas por esses empresários como relevantes para o sucesso empresarial e pessoal. Também acreditam que estão intimamente ligadas a suas práticas diárias, que podem ser compreendidas como ativadoras do aprendizado. Destacando-se a atenção e a dedicação para ouvir e atender aos feedbacks. E a participação em cursos, feiras e encontros setoriais. Os empresários afirmaram que, na medida em que foram percebendo os benefícios desses comportamentos, passaram a utilizá-los como uma estratégia intencional para obter os resultados desejados.
Com relação ao aprendizado, destacam-se a necessidade de reinvestir na empresa parte do lucro obtido; dedicar mais tempo e recursos na aquisição de novos conhecimentos; evitar o isolamento e a perda de contato com pessoas e novidades do setor, além de ampliar sua rede de contatos. Quando perguntados se conheciam empresários cujos comportamentos lhes davam a impressão de que pouco ou nada aprenderam com as experiências vividas, responderam afirmativamente acrescentando que: "viram muitos daqueles empresários se quebrarem". Houve concordância geral com o fato de que aqueles que desenvolveram aprendizados com as experiências parecem ter se tornado "pessoas mais empreendedoras que os outros". E que eles próprios sentem-se mais capazes e mais empreendedores.

Quando solicitados que relacionassem a aquisição de novos conhecimentos com o desenvolvimento de suas capacidades de reconhecer e aproveitar oportunidades, responderam que esses novos conhecimentos, com o tempo, passaram a ser utilizados de forma inconsciente. E, ainda, envolvem-se com maior frequência na criação ou no desenvolvimento de novos produtos, processos e/ou mercados. Fato que pode ser relacionado com a inovação, elemento indissociável do processo empreendedor.

Sobre excessos de otimismo, com uma exceção, responderam que ocorreu mais de uma vez, causando-lhes frustrações e desperdício de tempo e dinheiro. Além disso, afirmaram que atualmente priorizariam investimentos em atividades com alto grau de identificação pessoal e preferencialmente ligados a sua área de conhecimento e, indubitavelmente, munidos de uma consistente análise de viabilidade.

Quanto aos procedimentos gerenciais, todos utilizam algum tipo de ferramenta de controle financeiro, mesmo que rudimentar. A maioria utiliza procedimentos não formais de recepção e processamento de feedbacks que, são experimentados e, se aprovados, incorporados aos processos empresariais. 


\section{Apresentação do modelo}

O modelo foi idealizado e formatado a partir de contribuições teóricas do referencial bibliográfico e contribuições práticas, obtidas da observação e interpretação das atitudes e comportamentos assertivos dos sujeitos da pesquisa. Essa ligação entre o referencial teórico e as atitudes e comportamentos dos empresários entrevistados, sugere a possibilidade de que a replicação desses procedimentos é possível e pode contribuir para que outros empresários, em situações similares, obtenham resultados semelhantes.

\subsection{Os elementos do processo empreendedor}

A proposta desse modelo indica o empreendedor como elemento central a ser trabalhado. Nesse sentido, propõe um redirecionamento na forma como os empresários de MPEs criadas por necessidade, olham para si próprios, para a empresa e para o mundo. Essa transformação poderá ocorrer, pela estimulação para a percepção, incorporação e articulação dos elementos observados nos comportamentos dos entrevistados: a ativação emocional positiva, desencadeada pelo desejo e seguida por atitudes criativas; o desenvolvimento de uma visão de futuro desafiadora, mas alcançável; a utilização de procedimentos de conquista de alguma forma planejados e utilizados a partir da expertise empreendedor adquirida e adicionada ao repertório de habilidades de domínio desses empresários. Esse conjunto de elementos compõe grande parte do processo empreendedor e, embora com diferentes intensidades, sua presença ficou evidente em todos os entrevistados.

Esses elementos aparecem interinfluenciando-se e relacionando-se mutuamente com o ambiente em que estão inseridos, por meio das condições sociais, de mercado, políticas, demográficas e mudanças tecnológicas. Dessa forma, o empreendedor como elemento central do modelo proposto, possui em sua constituição psicológica e pragmática, a visão, a motivação, o planejamento e a inteligência empreendedor formando seu todo, conforme Figura 1.

Acredita-se que a utilização adequada e intencional dos elementos apresentados, venha representar a situação desejável para o desenvolvimento de micro e pequenos empresários e empresas.

\subsection{O modelo do sucesso empreendedor}

A convivência harmônica e sinérgica entre os elementos que compõem o cotidiano de empresários e MPEs tem sua realidade afetada, muitas vezes, de forma desarmônica por diversos fatores. Ao se deparar com essa realidade, e na empreitada de a ela fazer frente, o caminho mais sensato parece ser o da busca do desenvolvimento pessoal e da potencialização das qualidades empreendedoriais.

Nesse sentido, o modelo, representado na Figura 2, indica as ações e objetivos desejáveis para

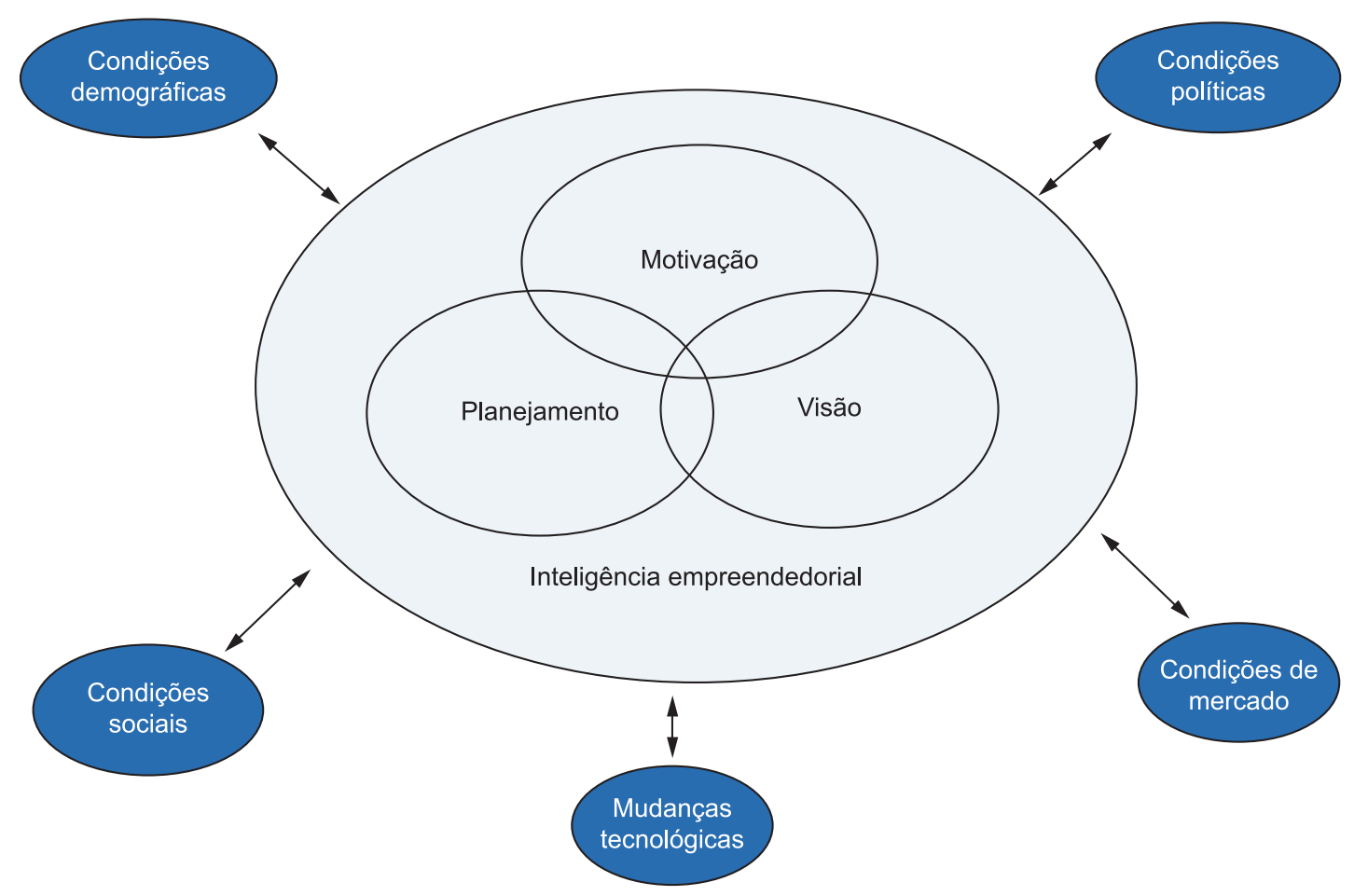

Figura 1. Representação esquemática dos elementos que compõem o processo empreendedor. 
o desenvolvimento das competências gerenciais que atendam às demandas empresariais, originadas a partir do impulso empreendedor. O modelo apresenta três etapas: A criação de um novo negócio ou uma nova atividade, estimulada pelo desejo ou necessidade de mudanças, sustentada pelo sonho a ser realizado e influenciada pelas alterações ambientais que, por sua vez, sofrem influências das ações e mudanças efetuadas. A experimentação empreendedor, na qual empreendedores são submetidos às dificuldades, sensações de desconforto e de ansiedade, impostas pelo mercado. Nesse contexto, desenvolvem percepções decorrentes das relações que estabelecem e, ao tomarem decisões, experimentam-se. Esse conjunto de fatores, reagindo entre si e se interinfluenciando provoca o desenvolvimento de aprendizados que, ao serem armazenados, combinados e utilizados ativam a inteligência empreendedor. Sendo, o meio, pródigo em mudanças, a demanda por novos conhecimentos é permanente e requer sua aquisição de forma imediata e pontual. Assim, na terceira etapa do processo, acontece a expansão intencional dos conhecimentos, objetivando o aumento da assertividade no desempenho das atividades empresariais e a conquista do sucesso empreendedor.

O Quadro 6 orienta o empreendedor para um conjunto de ações que, ao serem implementadas, complementam o modelo apresentado na Figura 2. Uma vez que sua aplicação potencializa o processo visionário, amplia o repertório de conhecimentos dos protagonistas e permite a experimentação de novas habilidades, favorecendo o estabelecimento da atuação empreendedora na gestão das MPEs.

Acredita-se que a aplicação desse modelo poderá suprir a demanda pelas competências necessárias para a gestão eficaz de MPEs. Pois a ativação da inteligência empreendedor, reforçada por ações coerentes e oportunas, orientadas para a solução

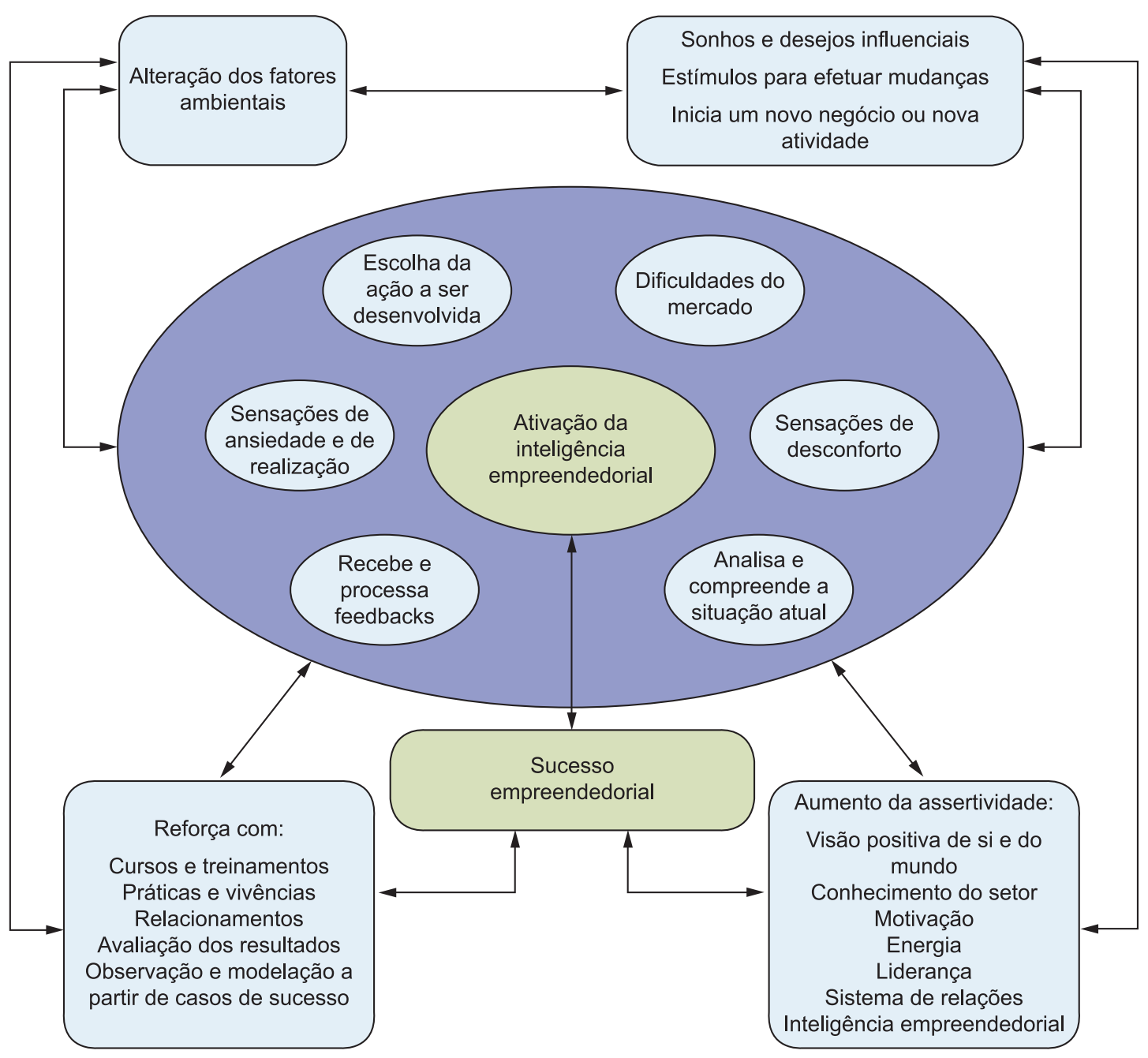

Figura 2. Modelo de ações e objetivos desejáveis para o desenvolvimento de competências gerenciais e conquista do sucesso empreendedor. 
Quadro 6. Competências, ações e objetivos desejáveis para a aquisição de competências empreendedoriais.

\begin{tabular}{|c|c|c|}
\hline Competências & Ações & Objetivos \\
\hline $\begin{array}{l}\text { Visão adequada de si e } \\
\text { do mundo }\end{array}$ & $\begin{array}{l}\text { Buscar feedback } \\
\text { Orientação profissional }\end{array}$ & $\begin{array}{l}\text { Desenvolver e apurar o senso crítico } \\
\text { Aumentar o grau de percepção assertiva } \\
\text { Favorecer julgamentos e decisões adequados }\end{array}$ \\
\hline $\begin{array}{l}\text { Conhecimento do setor } \\
\text { de atuação }\end{array}$ & $\begin{array}{l}\text { Participação em cursos, feiras e } \\
\text { eventos } \\
\text { Leituras especializadas } \\
\text { Experiências anteriores }\end{array}$ & $\begin{array}{l}\text { Aumentar as capacidades atuais e desenvolver } \\
\text { novas capacidades } \\
\text { Ampliar rede de contatos } \\
\text { Implantar melhorias }\end{array}$ \\
\hline Motivação & $\begin{array}{l}\text { Desenvolver a consciência da } \\
\text { importância do que faz, para si e } \\
\text { para seu sistema de relações }\end{array}$ & $\begin{array}{l}\text { Melhorar a autoestima e o conceito de si } \\
\text { Aumentar a autoconfiança } \\
\text { Energização }\end{array}$ \\
\hline Energia & $\begin{array}{l}\text { Priorizar a realização de tarefas } \\
\text { estimulantes e desafiadoras } \\
\text { Cuidar da saúde }\end{array}$ & $\begin{array}{l}\text { Promover alegria no trabalho } \\
\text { Aumentar a disposição para esforços } \\
\text { prolongados } \\
\text { Maior disposição para participar de situações } \\
\text { que permitam expandir a rede de contatos }\end{array}$ \\
\hline Liderança & $\begin{array}{l}\text { Participar de capacitações } \\
\text { com enfoque em liderança e } \\
\text { comunicação } \\
\text { Leituras especializadas }\end{array}$ & $\begin{array}{l}\text { Compreender o que é a liderança eficaz } \\
\text { Adotar o estilo adequado de liderança } \\
\text { situacional } \\
\text { Aumentar a capacidade de persuasão }\end{array}$ \\
\hline Sistema de relações & $\begin{array}{l}\text { Desenvolver a capacidade de } \\
\text { comunicação e de relacionamento } \\
\text { interpessoal }\end{array}$ & $\begin{array}{l}\text { Desenvolver a empatia e a capacidade de se } \\
\text { relacionar com pessoas e grupos de pessoas } \\
\text { Evitar dispêndio de energia } \\
\text { Melhorar a autoestima }\end{array}$ \\
\hline $\begin{array}{l}\text { Inteligência } \\
\text { empreendedor }\end{array}$ & $\begin{array}{l}\text { Ampliar rede de contatos } \\
\text { Conhecer o negócio com o qual está } \\
\text { envolvido } \\
\text { Desenvolver atividades que } \\
\text { estimulem o raciocínio, a memória e } \\
\text { os processos cognitivos }\end{array}$ & $\begin{array}{l}\text { Desenvolver as habilidades intelectuais } \\
\text { Ampliar a base de conhecimentos } \\
\text { Desenvolver um estilo de pensar criativamente } \\
\text { Tornar o ambiente de trabalho um local criativo } \\
\text { Adquirir uma personalidade empreendedora } \\
\text { Motivar-se intrinsecamente }\end{array}$ \\
\hline
\end{tabular}

de problemas e sustentadas pelas características pessoais positivas instaladas nessas pessoas, tornará explícito o sucesso empreendedor obtido por esses empreendedores. Uma premiação ao esforço pessoal realizado e poucas vezes reconhecido.

\section{Conclusão}

Aos olhos de um observador distraído parece não haver diferenças significativas entre empreendedores por necessidade, daqueles que criam suas empresas motivados pela identificação de uma oportunidade. Não obstante, elas existem e podem ser percebidas desde os primeiros atos de criação das empresas por necessidade. Basta acompanhar seus passos para perceber que seus comportamentos ansiosos e desconexos, em geral, não seguem uma trajetória coerente e planejada. Até porque, como se constatou, na maioria dos casos, não há planejamento algum.

É no campo dos objetivos que se pode encontrar algum grau de convergência entre esses dois tipos de criadores de empresas. Como exemplo dessa convergência, pode-se citar o desejo de ter seu próprio negócio, vê-lo prosperar, trabalhar com fluxo de caixa positivo e obter lucro. Essa convergência não os equipara em suas competências, antes, as denunciam. Em alguns poucos casos, esse fato é percebido pelos próprios empresários, induzindo-os à busca de recursos que os tornem mais competentes. Aos outros, os que não percebem as diferenças, o tempo e o mercado cobrarão o preço de sua distração, ou comodismo.

Ao se observar a trajetória dos empresários entrevistados, percebe-se que ela está ligada a uma forma de atuação que engloba processos de adaptação e de construção. Pode-se dizer que a habilidade na condução desses dois processos, foi responsável por fazer com que esses empresários e suas empresas alcançassem a situação na qual se encontram atualmente.

Adaptação às transformações que ocorreram no meio em que atuam e dizem respeito aos efeitos das mudanças sociais, ambientais, demográficas e legais ou normativas. Nesse ambiente de mudanças aconteceu, com cada um dos indivíduos pesquisados, a construção de um sistema de negócios moldado a partir da substituição de hábitos e procedimentos ultrapassados por novos conhecimentos e práticas que, ao serem utilizados, configuram-se em atitudes inovadoras. Poderosos agentes do desenvolvimento 
de um modelo de atuação empreendedor, mais adequado e apropriado à realidade interna e externa dessas MPEs.

A capacidade de adaptação e de construção, nos casos estudados, está relacionada a ações fortes e positivas, que se desenvolvem numa realidade em que alguns fatores definitivos para o sucesso, por serem do ambiente externo, em nada ou muito pouco podem ser alterados, apesar do desejo e do esforço aplicado pelos empreendedores em questão. Então, há que se adaptar a esta realidade. A observação dos fatos narrados leva a crer que a construção pode vir junto à adaptação, ou logo depois, mas não antes. Pois, se isso acontecer, podem ocorrer desconformidades na concepção ou na estratégia.

Pode-se dizer que os sujeitos da pesquisa, nesse estudo de caso, encontram-se em harmonia com as atividades que desenvolvem. Essa harmonia envolve a utilização consciente e inconsciente da capacidade de interligar e operar fatores pessoais e ferramentas de gestão ao ambiente no qual operam e fazem parte simultaneamente. Enquanto atuam, movidos pelo desejo de desenvolver e concretizar suas visões, estimulados pela motivação, gerada inicialmente pela necessidade de atender ao impulso interior de segurança e, em seguida, pela integração e adequação entre a personalidade do empreendedor e sua atividade. Orientados pelos planos de conquista e realização - alguns consistentes e palpáveis, outros quase intangíveis, mas presentes e persistentes. Os três elementos - visão, motivação e planejamento - acontecem e interinfluenciam-se mutuamente, enquanto influenciam e são influenciados por um quarto elemento, a inteligência empreendedor.

Agindo como interface entre os outros três, o desenvolvimento e a utilização da inteligência empreendedor, revela-se como fator definitivo para a obtenção de sucesso almejado. Ao realizarem as mudanças estimuladas pelos sinais e informações que, mesmo sem compreender como, perceberam, processaram e utilizaram adequadamente. Cada um, a sua maneira, de acordo com suas competências para articular determinados processos mentais, desenvolve suas capacidades.

Percebeu-se ainda que, na medida em que desenvolveram experiências empreendedoriais, foram acometidos pelo que se pode chamar de mudança de modelos mentais. Ocorreu então que seus modelos comportamentais também se alteraram. É bem provável que essa alteração comportamental tenha ocorrido pela influência de novos conceitos, internalizados a partir das relações estabelecidas com outros empresários, em capacitações, encontros setoriais e conversas formais e informais das quais participaram.

Os resultados orientam para o fato de que o processo visionário seguiu-se ao impulso emocional inicial de ter seu próprio negócio. Ao ser analisado sob o ponto de vista dessa teoria, o empreendedor pode ser caracterizado como o elemento catalisador de um relacionamento sinérgico entre ele, sua organização e o ambiente externo. Compondo, nessa triangulação, uma consistente rede de inter-relações.

Pode-se concluir que o comportamento desses empreendedores os tornou capazes de responder às situações críticas de forma rápida, flexível e com elevado grau de assertividade. Além disso, de acordo com Mitchell et al. (2007), os empreendedores são peritos na utilização de estruturas do conhecimento que lhes permitem utilizar as informações significativamente melhor que os não empreendedores, habilidade detentora de considerável significado na implementação de atitudes inovadoras e essencial ao processo empreendedor. Esse conjunto contribuiu para uma maior capacidade de perceber e utilizar as informações fundamentais para a formação de uma inteligência voltada para seus negócios. Fato que se constituiu numa vantagem competitiva para a empresa, no decorrer do seu desenvolvimento.

Não obstante essa possibilidade concreta, resta ainda um grande desafio: conseguir que o empresário passe a acreditar na possibilidade de mudar sua forma de pensar e de agir, tornando-se protagonista de sua caminhada para o sucesso, deixando, portanto, de ser mero expectador.

\section{Referências}

ANTUNES, C. As inteligências múltiplas e seus estímulos. Campinas: Papirus, 2000.

BARON, R. J.; SHANE, S. A. Empreendedorismo: Uma visão do Processo. São Paulo: Thomson Learning, 2007.

BAUMOL, W. J. Formal Entrepreneurship Theory in Economics: Existence and Bounds. Journal of Business Venturing, n. 3, p. 197-210, 1993. http://dx.doi. org/10.1016/0883-9026(93)90027-3

BAUMOL, W. J. Entrepreneurship in Economic Theory. The American Economic Review, n. 58, p. 64-71, 1968.

BAUMOL, W. J. Entrepreneurship: Productive, Unproductive, and Destructive. Journal of Political Economic, v. 98, n. 5, p. 893-921, 1990. http://dx.doi. org/10.1086/261712

BUCHANAN, J. M.; DI PIERRO, A. Cognition, Choice and Entrepreneurship. Southern Economic Journal, v. 46, p. 693-701, 1980. http://dx.doi.org/10.2307/1057139

CANTILLON, R. Essay sur la nature du commerce en general. London: Fetcher Gyler, 1755.

DOLABELA, F. Oficina do Empreendedor: A metodologia do ensino que ajuda a transformar conhecimento em riqueza. São Paulo: Cultura, 1999a.

DOLABELA, F. E depois da incubação? Uma metodologia inédita de Clube de empreendedores para apoio às empresas emergentes de base tecnológica. In: WORLD CONFERENCE ON INTERNATIONAL ENTREPRENEURSCHIP, 1999, Singapure. Proceedings... Singapure, 1999b. 
DOLABELA, F.; LIMA, M. Empreendedorismo, Uma Forma de Ser: Saiba o que são empreendedores individuais e coletivos. Brasília: AED, 2003.

DOLABELA, F.; LIMA, M. Entrepreneurship Learning in Brazilian Institutions of Higler Education. Curitiba, 2000.

DORNELAS, J. C. A. Empreendedorismo, Transformando Idéias em Negócios. São Paulo: Elsevier, 2005.

DRUKER, P. Inovação e espírito empreendedor. São Paulo: Pioneira, 1998.

FILION, L. J. Diferenças entre sistemas gerenciais de empreendedores e operadores de pequenos negócios. RAE - Revista de Administração de Empresas, v. 39, n. 4, p. 6-20, 1999. http://dx.doi.org/10.1504/ IJESB.2004.005376

FILION, L. J. O Planejamento do seu sistema de aprendizagem empresarial: Identifique uma visão e avalie o seu sistema de relações. RAE - Revista de Administração de Empresas, v. 31, n. 3, p. 63-71, 1991.

FILION, L. J. Operators and visionaries: differences in the entrepreneurial and managerial systems of two types of entrepreneurs. International Journal of Entrepreneurship and Small Business, v. 1, n. 1-2, p. 35-55, 2004.

FILION, L. J. Visão e relações: elementos para um metamodelo empreendedor. RAE - Revista de Administração de Empresas, v. 33, n. 6, p. 50-61, 1993.

FILION, L. J.; DOLABELA, F. Boa Idéia! E Agora? Plano de Negócio, o caminho seguro para criar e gerenciar sua empresa. São Paulo: Editora de Cultura, 2000.

GLOBAL ENTREPRENEURSHIP MONITOR - GEM. Global Entrepreneurship Monitor. Empreendedorismo no Brasil - Relatório Executivo, 2006. GEM, 2006.

GLOBAL ENTREPRENEURSHIP MONITOR - GEM. Global Entrepreneurship Monitor. Empreendedorismo no Brasil - Relatório Executivo, 2007. GEM, 2007.

GLOBAL ENTREPRENEURSHIP MONITOR - GEM. Global Entrepreneurship Monitor. Empreendedorismo no Brasil - Relatório Executivo, 2008. GEM, 2008.

GLOBAL ENTREPRENEURSHIP MONITOR - GEM. Global Entrepreneurship Monitor. Empreendedorismo no Brasil - Relatório Executivo, 2009. GEM, 2009.

GIL, A. C. Como Elaborar Projetos de Pesquisa. São Paulo: Atlas, 1996.

GOLEMAN, D. Inteligência Emocional. Rio de Janeiro: Objetiva, 1995.

MACHADO, N. J. Epistemologia e didática. São Paulo: Cortez, 1996.

McCLELLAND, D. C. Entrepreneurship and Achievement Motivation: Approaches to the Science of Socioeconomic Development. Paris: UNESCO, 1971.

McClelland, D. C. A Sociedade Competitiva. Rio de Janeiro: Expressão e Cultura, 1972.
MIGUEL, P. A. C. Estudo de caso na engenharia de produção: estruturação e recomendações para sua condução. Produção, v. 17, n. 1, p. 216-229, 2007. http://dx.doi.org/10.1590/S0103-65132007000100015

MITCHELL, R. K. et al. The Central Question in Entrepreneurial Cognition Research. Entrepreneurship: Theory and Practice, Baylor University, 2007.

PINCHOT, G. Intrapreneuring: Por que você não precisa deixar a empresa para se tornar um empreendedor. São Paulo: Harbra, 1989.

RICHARDSON, R. J. Pesquisa social: métodos e técnicas. 3. ed. São Paulo: Atlas, 1999.

SAY, J. B. De L'Angleterre et des Anglais. Paris: Arthur Bertrand, 1815.

SAY, J. B. England and the English People. 2. Edition by John Richter. London: Sherwood, Neely et Jones, 1816

SAY, J. B. Petit volume contenant quelques aperçus des hommes et de la société. 3. ed. Paris: Chez Guillaumin, Libraire, 1939.

SAY, J. B. Tratado de economia política. Prefácio de Georges Tapinos; tradução de Balthazar Barbosa Filho; tradução do prefácio de Rita Valente Correia Guedes. São Paulo: Abril Cultural, 1983.

SCHUMPETER, J. A. History of economic analysis. Edited by Elizabeth Boody Schumpeter. New York: Oxford University Press, 1954.

SCHUMPETER, J. A. Teoria do desenvolvimento econômico: Uma investigação sobre lucros. São Paulo: Nova Cultural, 1997.

SERAFIN, M. C.; LEÃO I. Uma perspectiva Italiana do Empreendedorismo: Entrevista com Alberto Martinelli. RAE-eletrônica, v. 6, 2007. Disponível em: <http// www.rae.com.br/eletrônica>. Acesso em: 04 dez. 2007.

SHANE, S.; VENKATARAMAN. S. (2000) The Promise of Entrepreneurship as a Field of Research. The Academy of Management Review, v. 25, n. 1, p. 217-226, 2000. http://dx.doi.org/10.2307/259271

STERNBERG, R. J. Successful Intelligence as a basic for entrepreneurship. Journal of Business Venturing, 2004.

TIMMONS, J. A. Motivating economic achievement: a five-year appraisal. In: AMERICAN INSTITUTE OF DECISION SCIENCES, 1973, Boston. Proceedings... Boston, 1973.

TRIVIÑOS, A. N. S. Introdução à Pesquisa em Ciências Sociais: A Pesquisa Qualitativa em Educação. São Paulo: Atlas, 2006.

WEBER, M. The Protestant Ethic and the Spirit of Capitalism. Translated by Talcott Parsons. London: Allen \& Unwin, 1930.

YIN, R. K. Estudo de caso: planejamento e métodos. Porto Alegre: Bookman, 2001. 